Supporting Information for:

\title{
Addition of $\mathrm{Sn}-\mathrm{O}^{i} \mathrm{Pr}$ across a $\mathrm{C}=\mathrm{C}$ Bond: Unusual Insertion of an Alkene into a Main-Group-Metal-Alkoxide Bond
}

Evgeny V. Beletskiy, ${ }^{a}$ Yuyang Wu, ${ }^{b}$ Mayfair C. Kung, ${ }^{* a}$ and Harold H. Kung*a

${ }^{a}$ Chemical and Biological Engineering Department and ${ }^{\mathrm{b}}$ Chemistry Department, Northwestern University, Evanston, IL. 60208, USA.

\section{Contents}

Page

Methods and materials S2

Synthesis details for $\mathbf{3}$ $\mathrm{S} 2$

Figure S1: ${ }^{1} \mathrm{H}$ NMR spectrum of $\mathbf{3}$ S3

Figure S2: ${ }^{13} \mathrm{C}$ NMR spectrum of $\mathbf{3}$ S4

Figure S3: ${ }^{29} \mathrm{Si}$ NMR spectrum of $\mathbf{3}$ S5

Figure S4: ${ }^{119}$ Sn NMR spectrum of $\mathbf{3}$ S6

Figure S5a: COSY NMR spectra of $3 \quad$ S7

Figure S5b: Cross-peak correlations in COSY spectra of $\mathbf{3} \quad$ S7

Figure S6a: HSQC NMR spectra of $\mathbf{3} \quad$ S8

Figure S6b: Cross-peak correlations in HSQC spectra of $\mathbf{3}$ S8

Figure S7a: HMBC NMR spectra of $\mathbf{3}$ S9

Figure S7b: Cross-peak correlations in HMBC spectra of $\mathbf{3} \quad$ S9

Figure S8: ${ }^{119}$ Sn NMR spectrum of $\mathbf{3}$ without proton decoupling $\quad$ S10

Figure S9: ${ }^{1} \mathrm{H}$ NMR spectra of $\mathbf{3}$ with and without ${ }^{119}$ Sn decoupling $\quad$ S11

Figure S10a: ESI-MS spectrum of $\mathbf{3} \quad \mathrm{S} 12$

Figure S10b: ESI-MS spectrum expansion and predicted peak intensities $\quad$ S12 


\section{Methods and materials}

Chemicals. All chemicals and solvents were purchased from Sigma-Aldrich, except tin isopropoxide from Gelest Inc.

Characterization. Bruker Avance III 500 was used for ${ }^{1} \mathrm{H}$ and ${ }^{13} \mathrm{C}$ NMR experiments, whereas Agilent DD MR-400 system was used for heteronuclear NMR methods. All spectra were obtained utilizing sealed J Young NMR tubes. Agilent 6210A LC-TOF mass spectrometer was utilized for ESI-MS analysis.

\section{Synthesis}

Sn-silsesquioxane. To a Schleck flask containing a solution of tin isopropoxide isopropanol adduct $(65.5 \mathrm{mg}, 157 \mu \mathrm{mol})$ in dry toluene $(2 \mathrm{~mL})$ under nitrogen atmosphere was added ligand 1 $(130 \mathrm{mg}, 123 \mu \mathrm{mol})$ in dry toluene $(2 \mathrm{~mL})$ at ambient temperature dropwise over $1 \mathrm{~min}$. The solution was stirred for $5 \mathrm{~min}$ and a small amount of thick white precipitate formed. The mixture was then gradually heated to $100^{\circ} \mathrm{C}$ and stirred for $30 \mathrm{~min}$. During this time the amount of the precipitate initially increased, but after $c a .15$ min dissolved completely to form a yellow solution. Vacuum has applied gently and the volatiles were removed at $100^{\circ} \mathrm{C}$. The resulting yellow solid was further dried at this temperature for $5 \mathrm{~min}$, dissolved in $\mathrm{CDCl}_{3}$ and analyzed as is without further purification. ${ }^{1} \mathrm{H} \mathrm{NMR}\left(500 \mathrm{MHz}, \mathrm{CDCl}_{3}\right) \delta 4.46(\mathrm{sept}, J=6.0 \mathrm{~Hz}, 1 \mathrm{H}$, $\left.\mathrm{SnOCHMe}_{2},{ }^{3} J\left({ }^{119} \mathrm{Sn}-{ }^{1} \mathrm{H}\right)=50 \mathrm{~Hz}\right), 3.92\left(\mathrm{t}, J=7.9 \mathrm{~Hz}, 1 \mathrm{H}, \mathrm{H}_{\mathrm{X}}\right.$ of $\mathrm{CH}_{\mathrm{A}} \mathrm{CH}_{\mathrm{M}} \mathrm{H}_{\mathrm{X}},{ }^{3} J\left({ }^{119} \mathrm{Sn}-{ }^{1} \mathrm{H}\right)=$ $265 \mathrm{~Hz}), 3.84$ (sept, $\left.J=6.0 \mathrm{~Hz}, 1 \mathrm{H}, \mathrm{COCHMe}_{2}\right), 3.51$ (dd, $J=11.8,7.6 \mathrm{~Hz}, 1 \mathrm{H}, \mathrm{H}_{\mathrm{M}},{ }^{3} J\left({ }^{119} \mathrm{Sn}-\right.$ $\left.\left.{ }^{1} \mathrm{H}\right)=55 \mathrm{~Hz}\right), 2.08\left(\mathrm{dd}, J=11.8,8.1 \mathrm{~Hz}, 1 \mathrm{H}, \mathrm{H}_{\mathrm{A}},{ }^{2} J\left({ }^{119} \mathrm{Sn}-{ }^{1} \mathrm{H}\right)=160 \mathrm{~Hz}\right), 1.88-1.71(\mathrm{~m}, 35 \mathrm{H})$, $1.37-1.20(\mathrm{~m}, 47 \mathrm{H}), 0.82-0.72(\mathrm{~m}, 7 \mathrm{H}), 0.32(\mathrm{~s}, 3 \mathrm{H}), 0.27(\mathrm{~s}, 3 \mathrm{H}) .{ }^{13} \mathrm{C} \mathrm{NMR}\left(126 \mathrm{MHz}, \mathrm{CDCl}_{3}\right)$ $\delta 72.88\left(\mathrm{OCHMe}_{2}\right), 66.53\left(\mathrm{SnOCHMe}_{2}\right), 63.47\left(\mathrm{CH}_{2} \mathrm{O}\right), 33.94$ (SiCHSn), 27.87, 27.85, 27.67, 27.64, 27.61, 27.58, 27.39, 27.34, 27.32, 27.28, 27.22, 27.05, 27.01, 26.97, 26.94, 26.85, 26.83, 26.79, 26.77, 26.73, 26.65 ( $\mathrm{CH}_{2}$ 's of $c$-Hexyl), 25.20, 24.86, 24.54, 23.92, 23.81, 23.50, 23.25

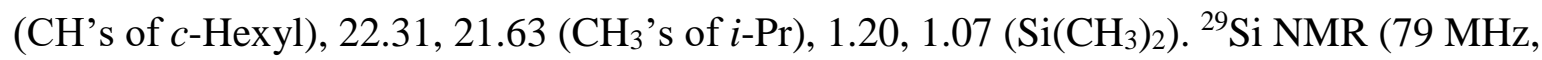
$\left.\mathrm{CDCl}_{3}\right) \delta 3.39,-66.00,-66.65,-68.15,-69.11,-70.27,-70.51,-70.63 .{ }^{119} \mathrm{Sn}$ NMR (149 MHz, $\mathrm{CDCl}_{3}$ ) $\delta-311.80$ (s with ${ }^{1} \mathrm{H}$ decoupling; ddt without ${ }^{1} \mathrm{H}$ decoupling, $J=266,161,53 \mathrm{~Hz}$ ). HRMS (ESI) $m / z$ calcd for $\mathrm{C}_{49} \mathrm{H}_{93} \mathrm{O}_{13} \mathrm{Si}_{8} \mathrm{Sn}\left(\mathrm{M}-\mathrm{C}_{3} \mathrm{H}_{7} \mathrm{O}\right)^{+} 1233.3799$, found 1233.3792 . 

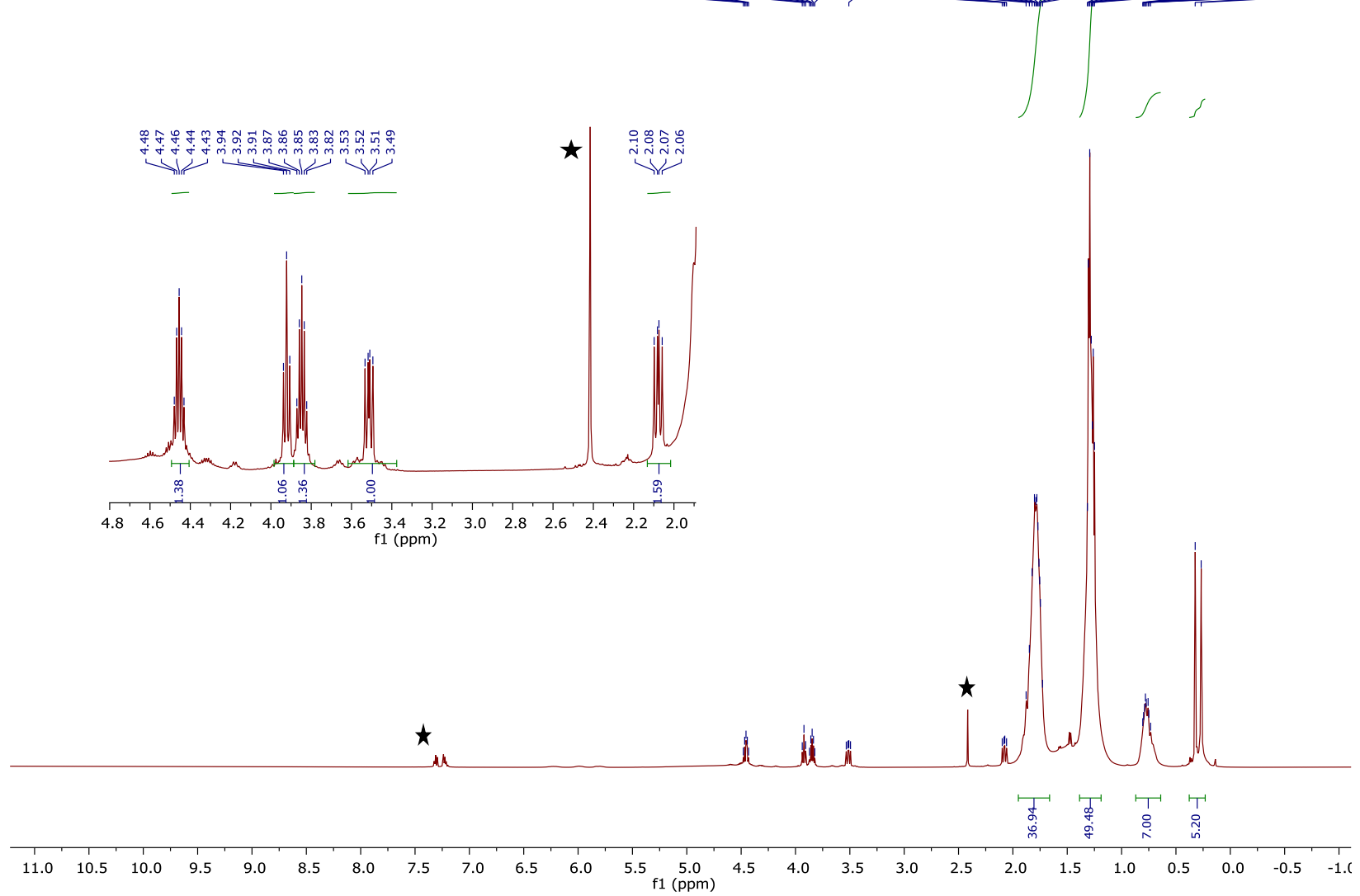

Figure S1. ${ }^{1} \mathrm{H}$ NMR spectrum of 3 in $\mathrm{CDCl}_{3}(500 \mathrm{MHz})$. Integrations in the $\delta 2.0-0.0 \mathrm{ppm}$ and 5.0-2.0 regions were done separately due to baseline correction difficulties. Residual toluene signals are marked with asterisks. 

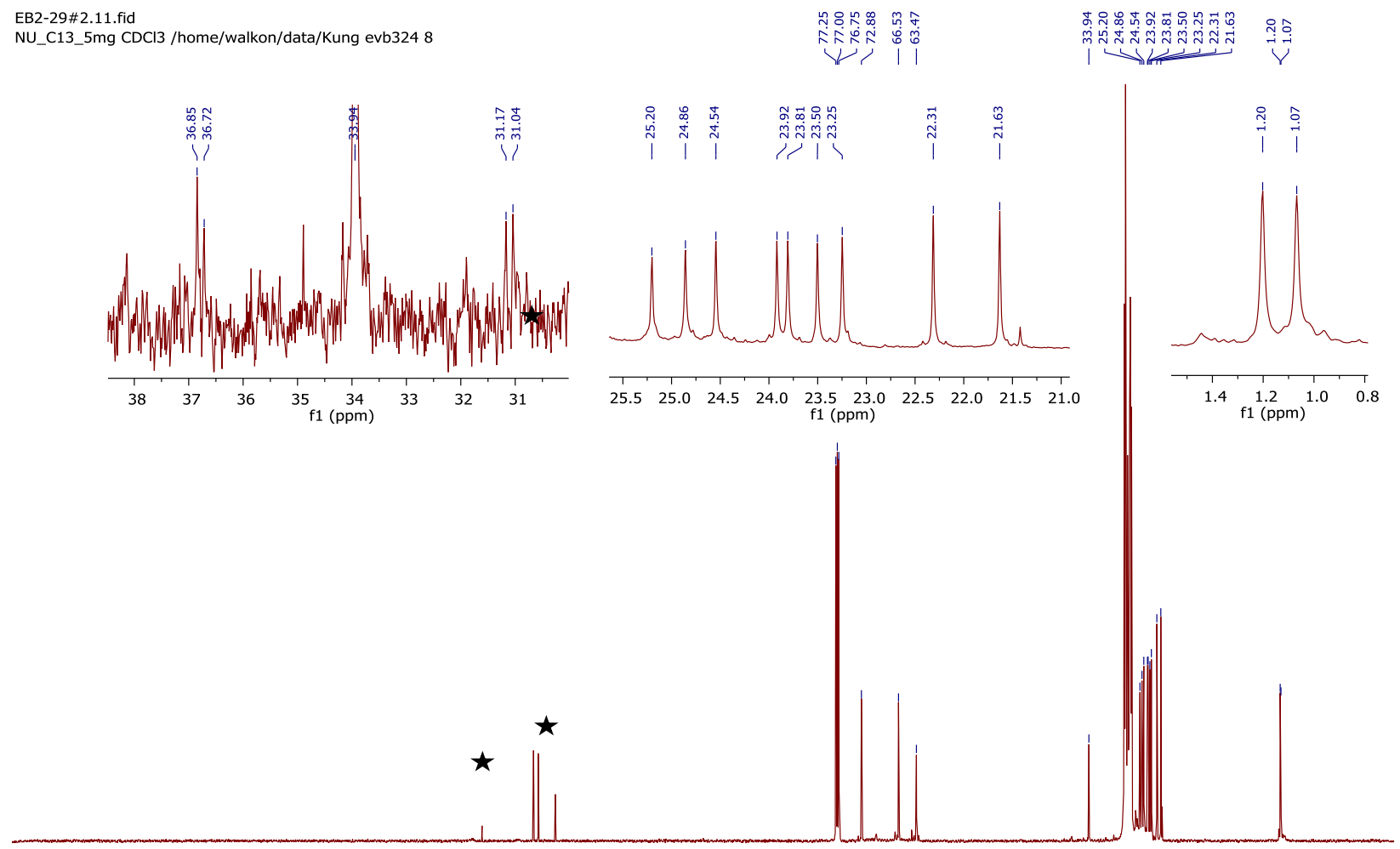

\begin{tabular}{llllllllllllllllllllllll}
\hline & 210 & 200 & 190 & 180 & 170 & 160 & 150 & 140 & 130 & 120 & 110 & 100 & 90 & 80 & 70 & 60 & 50 & 40 & 30 & 20 & 10 & 0 & -10
\end{tabular}

Figure S2. ${ }^{13} \mathrm{C}$ NMR spectrum of $\mathbf{3}$ in $\mathrm{CDCl}_{3}(126 \mathrm{MHz})$. Residual toluene signals are marked with asterisks. The upper left insert demonstrates the satellites resulting from the $\mathrm{Sn}-\mathrm{C}$ coupling interactions with ${ }^{1} J\left({ }^{13} \mathrm{C}-{ }^{119} \mathrm{Sn}\right)=731 \mathrm{~Hz}$ and ${ }^{1} J\left({ }^{13} \mathrm{C}-{ }^{117} \mathrm{Sn}\right)=699 \mathrm{~Hz}$. 
EB2-29\#2-Si29

Hg400 RT 26C nonspin

sample ATFI

2015-08-05

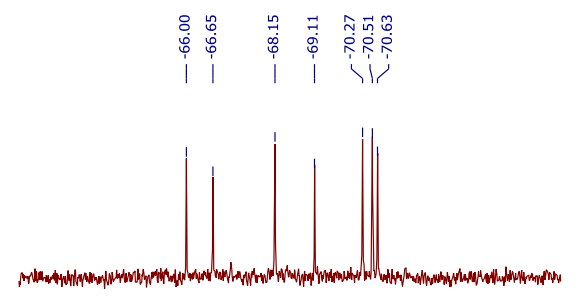

\begin{tabular}{llllllllllllll}
-62 & -63 & -64 & -65 & -66 & -67 & -68 & -69 & -70 & -71 & -72 & -73 & -74 & -75 \\
& & \multicolumn{1}{c}{$(\mathrm{ppm})$}
\end{tabular}

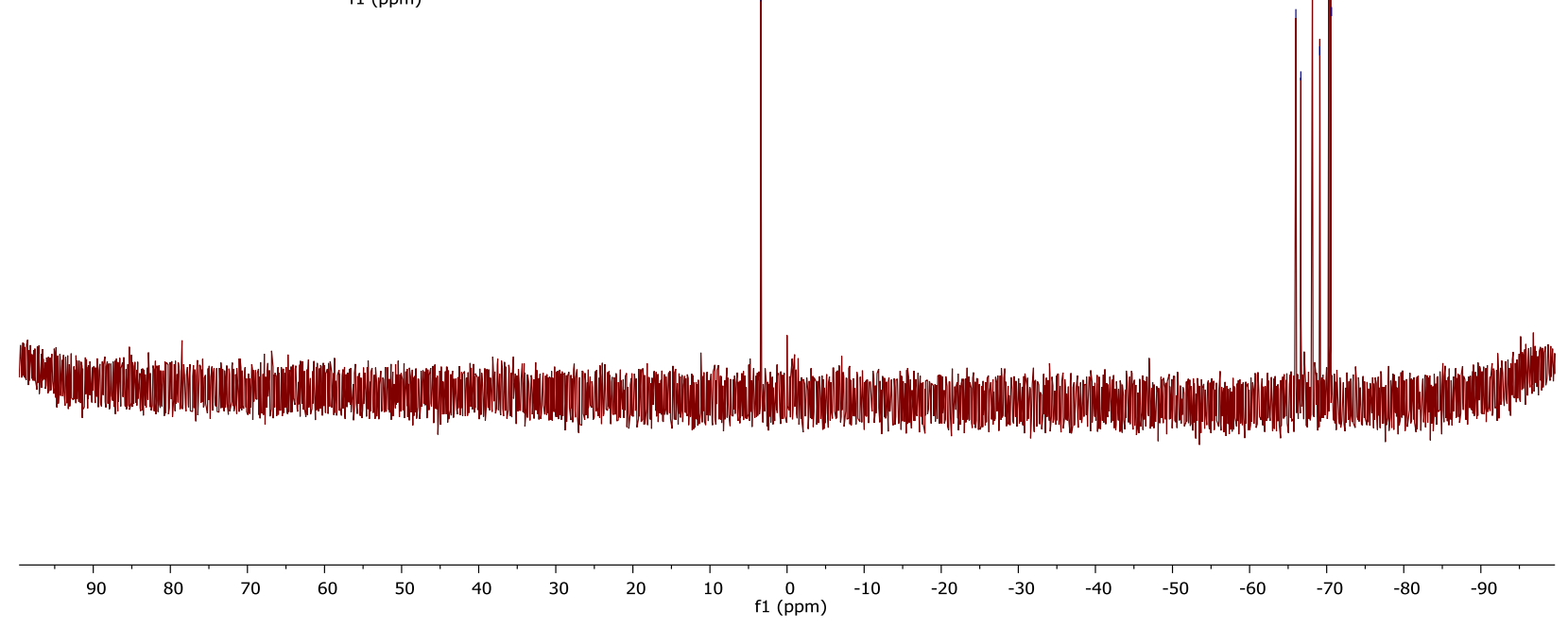

Figure S3. ${ }^{29} \mathrm{Si}$ NMR spectrum of 3 in $\mathrm{CDCl}_{3}(79 \mathrm{MHz})$. 


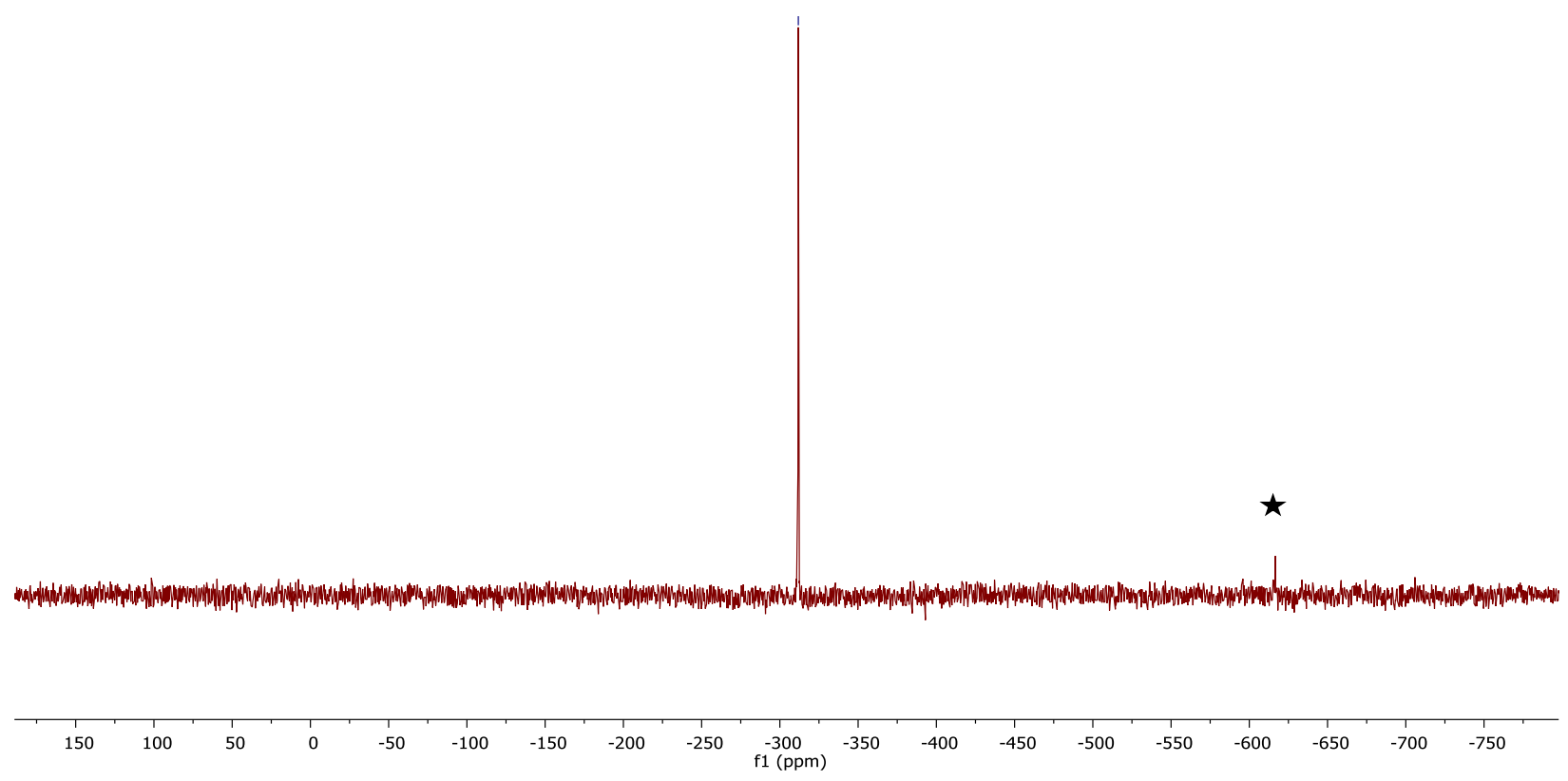

Figure S4. ${ }^{119} \mathrm{Sn}$ NMR spectrum of 3 in $\mathrm{CDCl}_{3}(149 \mathrm{MHz})$. Residual $\mathrm{Sn}$ isopropoxide signal is marked with an asterisk. 


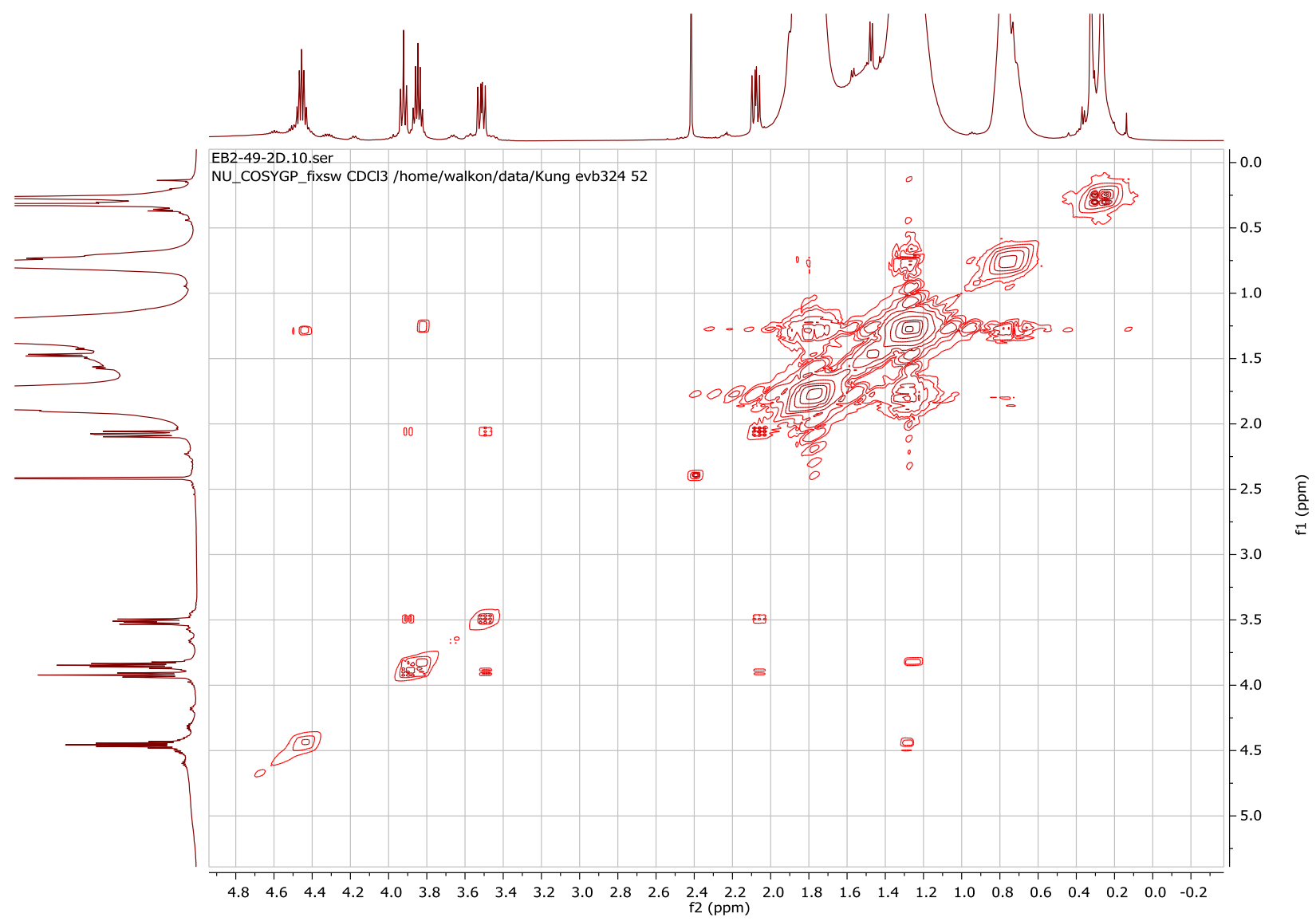

Figure S5a. COSY NMR spectra of $\mathbf{3}$ in $\mathrm{CDCl}_{3}$.

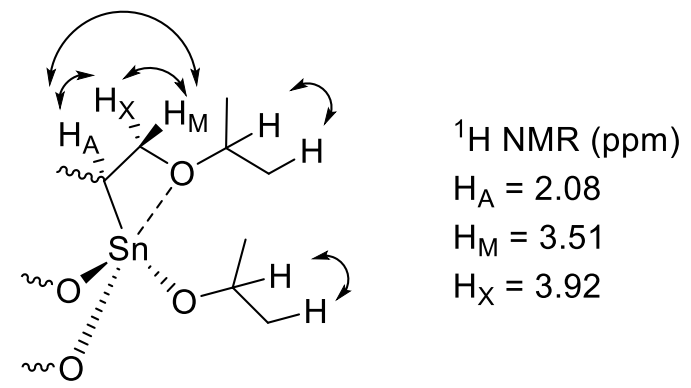

Figure S5b. Cross-peak correlations observed in the COSY spectra of 3. 


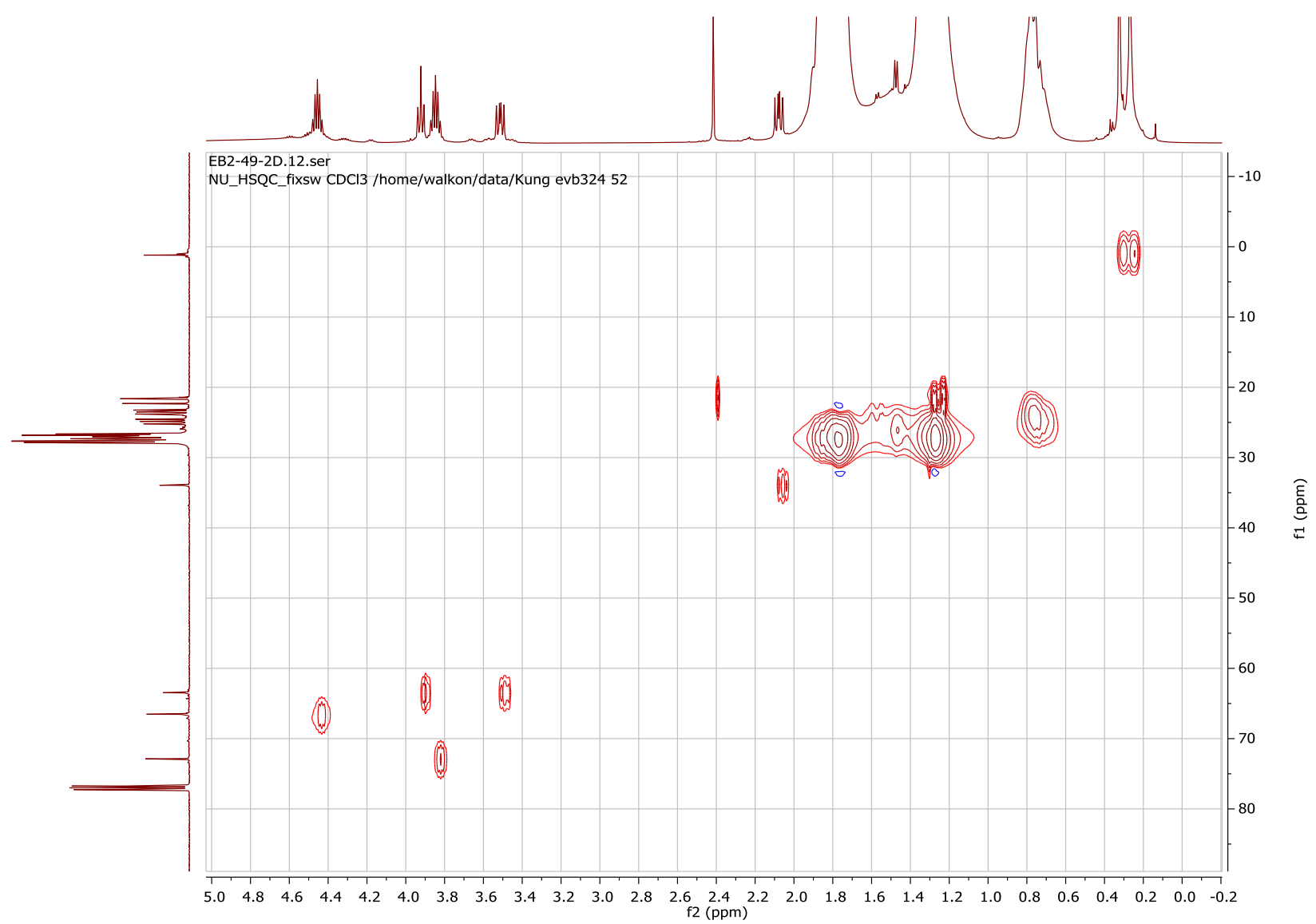

Figure S6a. HSQC NMR spectra of $\mathbf{3}$ in $\mathrm{CDCl}_{3}$.
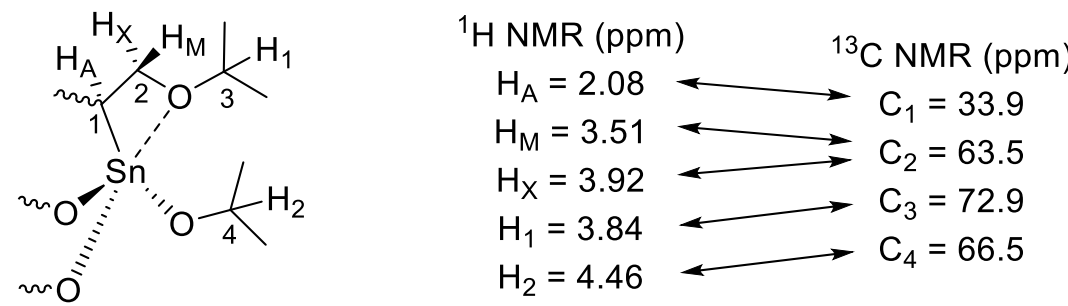

Figure S6b. Key single-bond C-H correlations observed in the HSQC spectra of 3. 


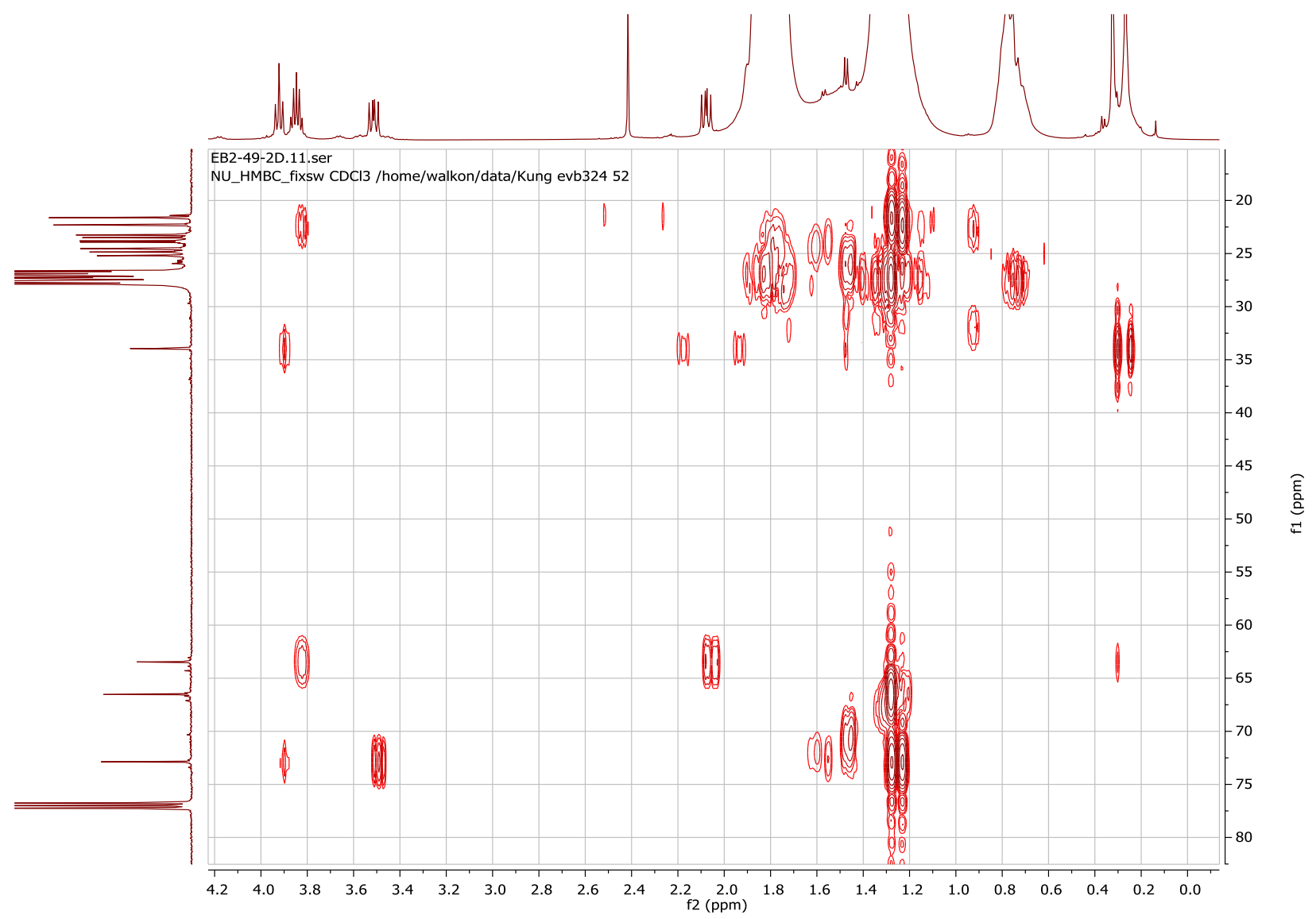

Figure S7a. HMBC NMR spectra of $\mathbf{3}$ in $\mathrm{CDCl}_{3}$.
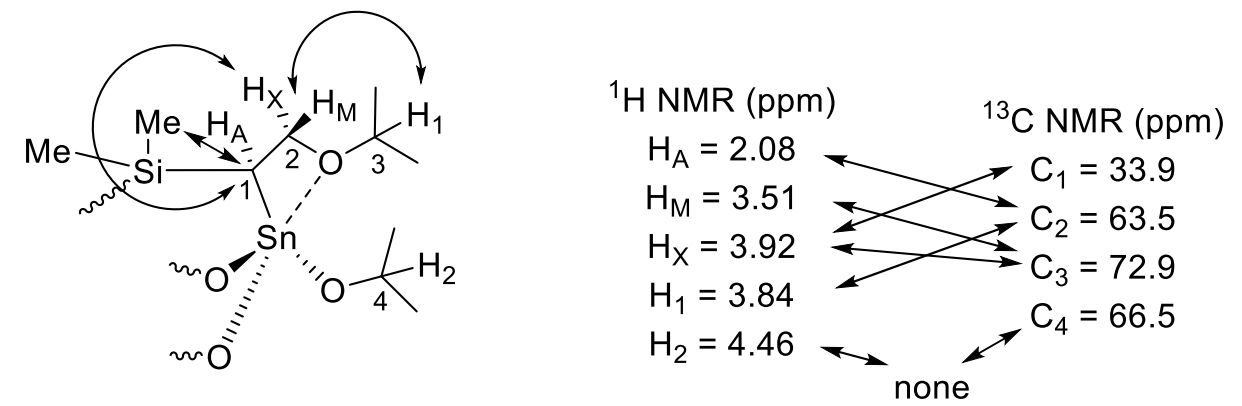

Figure S7b. Key multi-bond C-H correlations observed in the HMBC spectra of $\mathbf{3}$. 


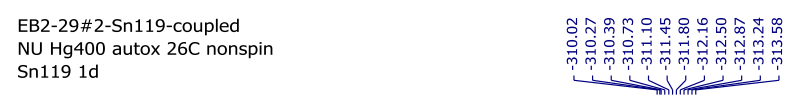

119Sn NMR (149 MHz, Chloroford) $-\delta-311.80(\mathrm{ddt} J=266.1,161.2,53.4 \mathrm{~Hz})$.
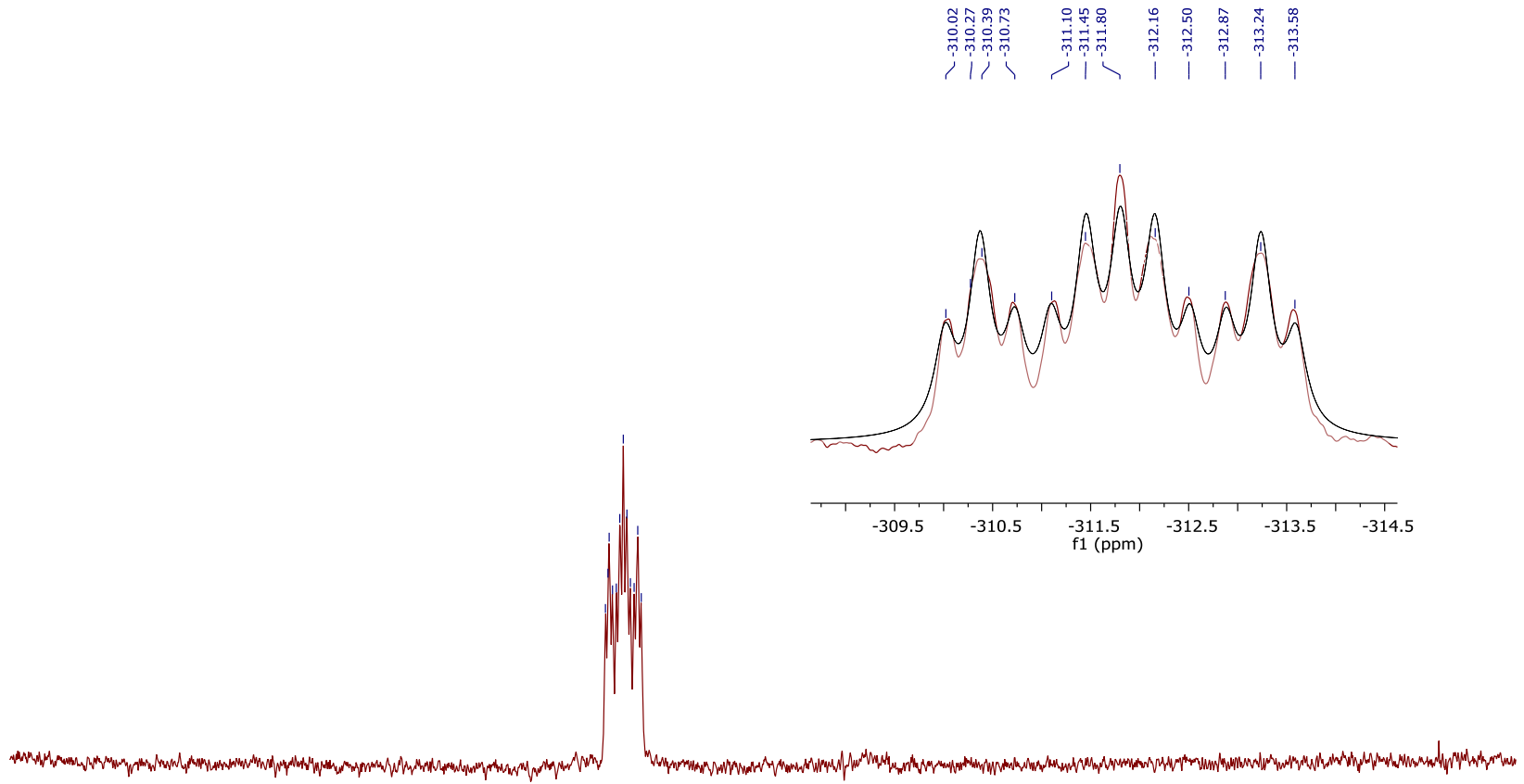

$\begin{array}{llllllllllllllllllllllllllllllllllllllllllllllll}-255 & -260 & -265 & -270 & -275 & -280 & -285 & -290 & -295 & -300 & -305 & -310 & -315 & -320 & -325 & -330 & -335 & -340 & -345 & -350 & -355 & -360 & -365 & -370 & -375 & -380 & -385 & -390 & -395 & -41\end{array}$

Figure S8. ${ }^{119} \mathrm{Sn} \mathrm{NMR}$ spectrum of $\mathbf{3}$ in $\mathrm{CDCl}_{3}(149 \mathrm{MHz})$ without proton decoupling. Insert: Expansion of the multiplet (solid maroon line) and a simulation of the doublet of doublets of triplets with $J=266,161$ and $53 \mathrm{~Hz}$ (dashed black line). 


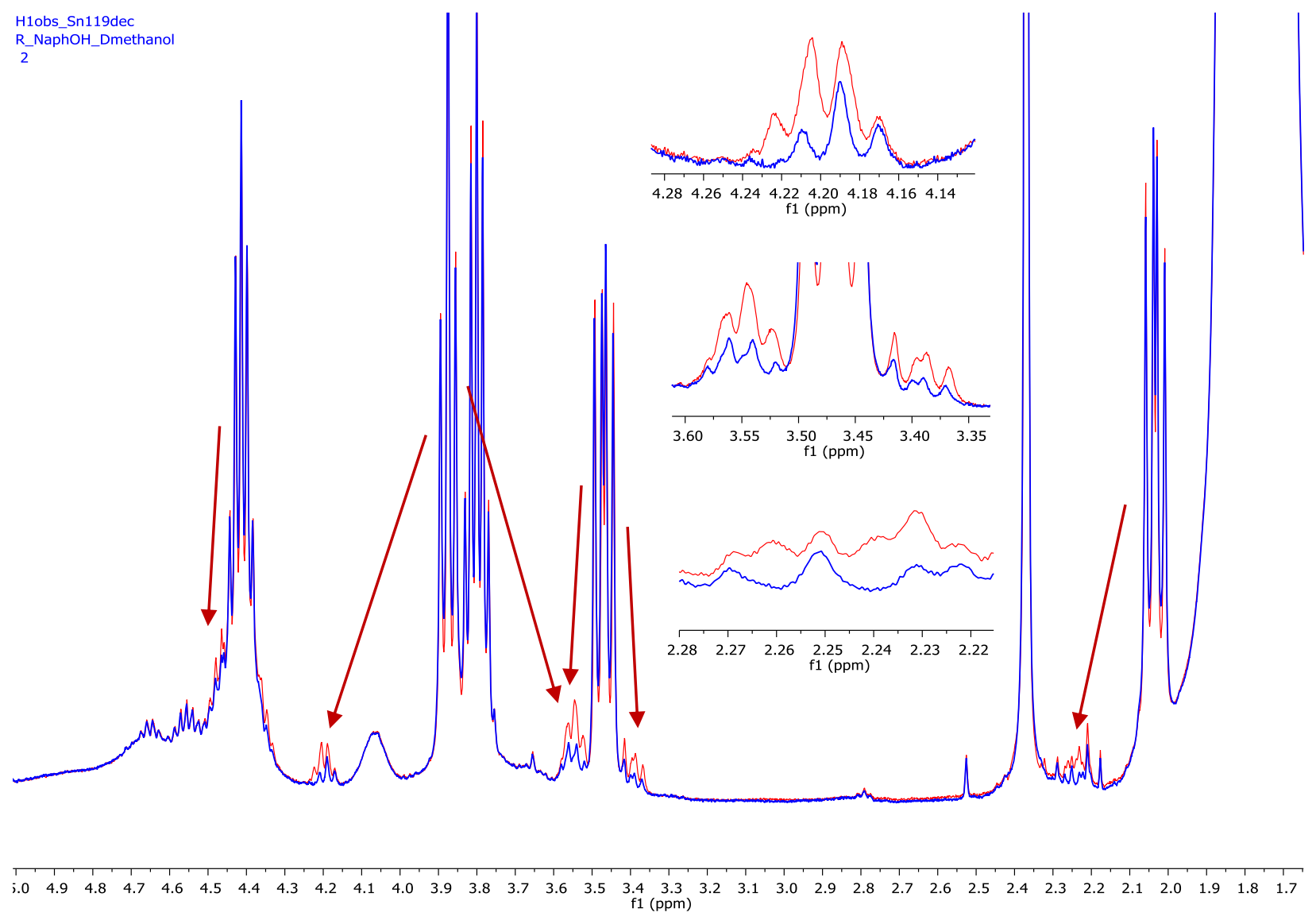

Figure S9. ${ }^{1} \mathrm{H}$ NMR spectra of $\mathbf{3}$ in $\mathrm{CDCl}_{3}\left(400 \mathrm{MHz}\right.$ ) with (blue) and without (red) ${ }^{119} \mathrm{Sn}$ decoupling. Blue spectra contain only ${ }^{117} \mathrm{Sn}$ interactions and thus the satellite peak intensities are decreased and more symmetrical. Arrows demonstrate the parent peak - satellite peak relationships. 


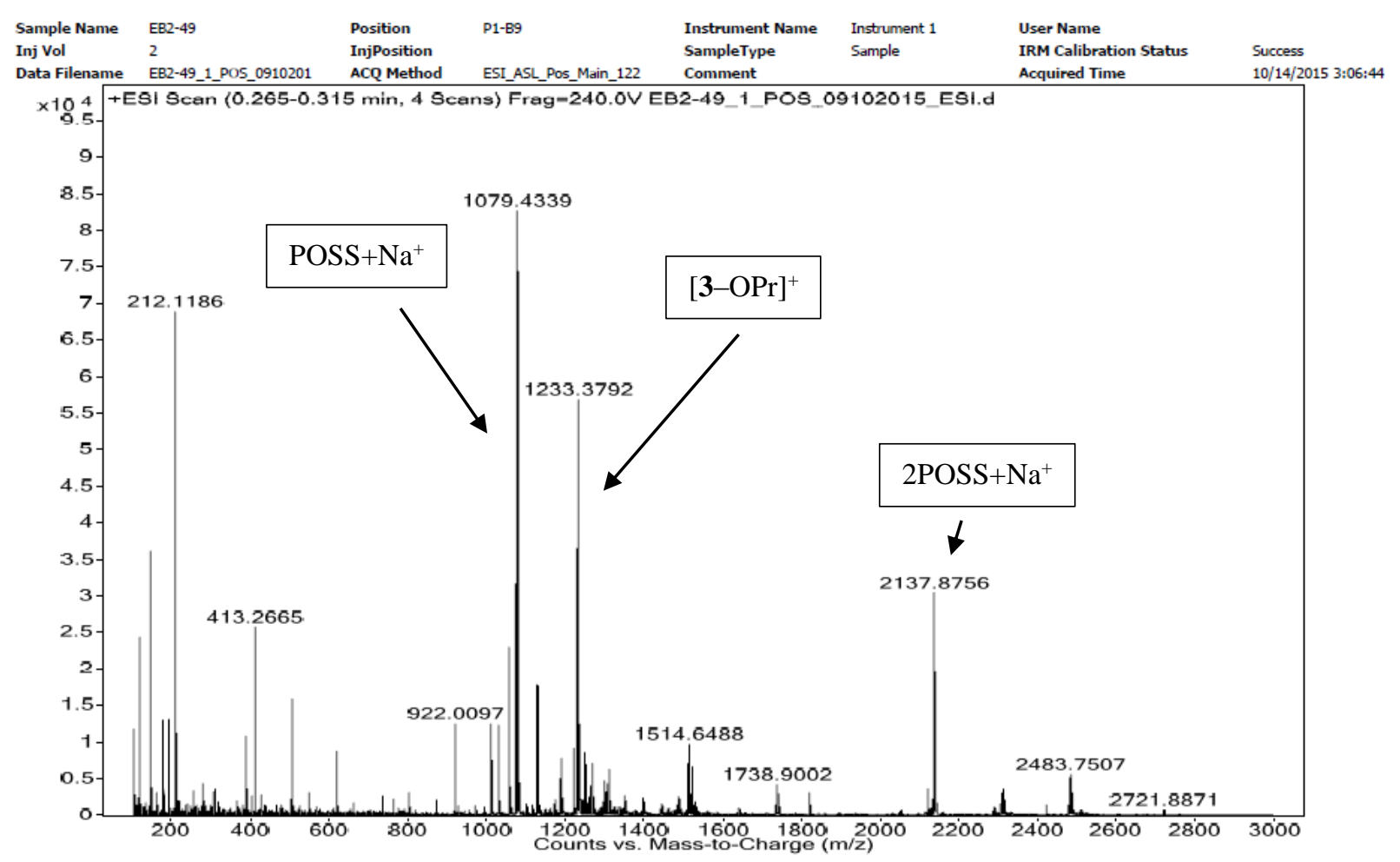

Figure S10a. ESI-MS of 3 in $\mathrm{CDCl}_{3}$. Spectrum contains $[3-\mathrm{OPr}]^{+}$with the positive charge presumably localized on Sn, and POSS ligand signals possibly resulting from the hydrolysis of $\mathbf{3}$.

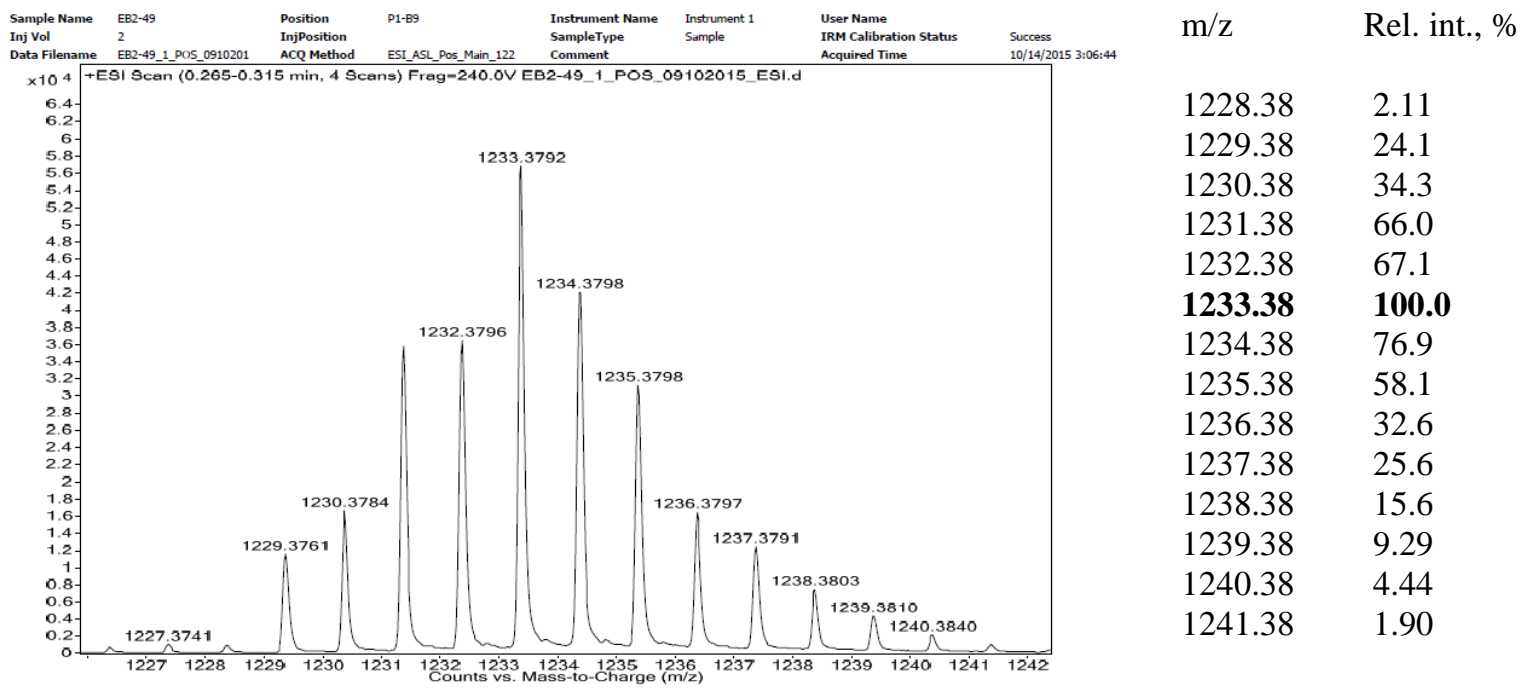

Figure S10b. Expansion of the ESI-MS spectrum of 3 in $\mathrm{CDCl}_{3}$ at $[\mathbf{3}-\mathrm{OPr}]^{+}$(left). Calculated $\mathrm{m} / z$ and the relative peak intensities for the isotope pattern of $\mathrm{C}_{49} \mathrm{H}_{93} \mathrm{O}_{13} \mathrm{Si}_{8} \mathrm{Sn}^{+}$(right). 